\title{
From continence as a learned behavior to the subspecialty
}

\author{
John Andrew Fantl
}

Published online: 5 December 2014

(C) The International Urogynecological Association 2014

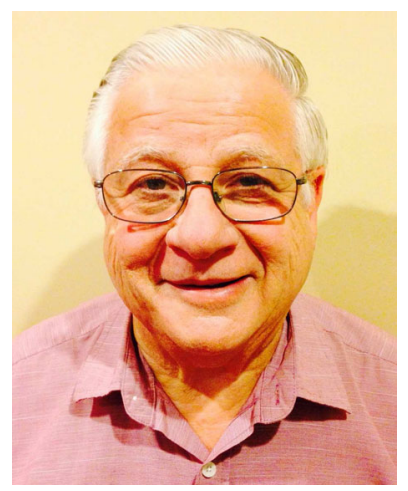

Writing a short article on a $40+$-year career is a bit like performing surgery: no matter how careful and accurate you are, there is inevitably going to be some bleeding. So I ask for understanding and forgiveness from the many deserving people whom I do not mention here.

I have had the good fortune to work in an exciting area that has finally gained recognition as a sub-specialty of obstetrics and gynecology in the USA. I claim no credit for this; countless individuals, with different skills but with one purpose - to produce evidence-based data supporting diagnostic and treatment modalities - led to the recognition of female pelvic medicine and reconstructive surgery (urogynecology) as a subspecialty.

\section{Early days: a mentor and an enduring friend}

I arrived in Nassau County, NY from Buenos Aires, Argentina in May of 1970 with one suitcase, a debt to my beloved

J. A. Fantl $(\bowtie)$

Mount Sinai-Beth Israel Medical Center, 317 17th St., New York, NY 10003, USA

e-mail: fantlja1@gmail.com mother for the plane fare, and a dream of being a good doctor. East Meadowbrook Hospital, where I interned, was slated to become Stony Brook University Hospital, but instead became Nassau County Medical Center. During my internship yearthe worst and the best year of my life-I learned a mountain and slept almost never (there were no maximum hours of work for interns and residents in those days).

I must have done something right during that year because at the end I received a letter accepting me as a resident in the department of Obstetrics and Gynecology at the Medical College of Virginia, Virginia Commonwealth University. That turned my life in the right direction.

The chairman of the department, Dr. Leo J. Dunn, became my teacher, my mentor, and, throughout the years, my friend. $\mathrm{He}$ is a unique man: master clinician and surgeon with a remarkable sense of fairness as well as superb administrative capabilities. He led his department to become one of the best in the nation. His perspective was free of political or financial interest; he was focused on superb patient care, departmental stability, and the fostering of his residents' development. He taught by example and gave me, personally, the opportunity to develop my professional goals. His support made things happen.

\section{Continence as a learned behavior}

It was during the late 70 s that I learned about bladder drill. An article by Jeffcoate and Francis [1] described the successful use of behavioral techniques in the management of female urinary incontinence. I was immediately interested. This may not seem like a radical idea today, but back then the most accepted approaches to female incontinence were Kegel's exercises, pharmaceuticals, and, predominantly, surgery.

Conceptually this form of management stems from the fact that continence represents, in fact, a learned, social behavior. 
Any learned behavior may be lost, but can also be regained. Jeffcoate and Francis established a regimen (charmingly) named "bladder drill" and conducted their intervention in a controlled, hospital environment.

To make this approach practical in the USA, two things had to happen. First of all, develop ways to have the patient conduct the bladder drill on an outpatient basis in order to make it less costly. This involved giving easy-to-follow instructions and a method of personal accountability (clock faces on small cards on which patients marked their compliance with a pre-agreed voiding schedule). Secondly, assemble and analyze data that would establish the efficacy of this approach in a scientifically sound manner.

\section{A patient provides positive reinforcement}

During the preliminary days and before the actual research protocol was started, I became convinced of the value of the behavioral approach by a patient whom I treated with this therapy. At our first meeting, she was disheveled, looked much older than her age, and seemed profoundly depressed. When she came in for her third or fourth appointment, my nurse told me I had to go and take a look at her sitting in the waiting room. The patient had transformed; she looked great and seemed totally radiant. She was one of the most grateful patients I have encountered during my career.

This was the first of countless occasions on which I have been able to say, "Instead of your bladder controlling you, you are finally controlling your bladder." The change had been effected without side effects or risk factors. I became an advocate for the idea that our armamentarium should include a behavioral approach in addition to surgery, pharmaceuticals, and pelvic floor rehabilitation.

\section{Alignment with government concerns (being at the right place at the right time)}

As it turned out, at that time the government was eager to have research done into incontinence. Incontinence was one of the major reasons why patients were admitted to residential care facilities. The aging of America was now fully recognized, and its social and economic effects clear. This scenario most likely influenced my ability to obtain federal funding to pursue the study of the effect of a form of behavioral management on patients with urinary incontinence

An article entitled "Efficacy of bladder training in older women with urinary incontinence" [2] was my team's first contribution to the literature of our subspecialty. It is still regarded today as our most relevant contribution.

\section{The continence program for women}

Further federal funding followed. This allowed the assembly of a team of invaluable, talented professionals who cooperated together under the heading "Continence Program For Women." The project was based at The Medical College of Virginia, with additional sites at Duke University and Wake Forest University. It was an honor to work with stellar colleagues including: W. Glenn Hurt (who actually brought the initial technology to our department from C. Paul Hodgkinson's laboratory), Richard C. Bump, J. F. Wyman, S. W. Harkins, D.K. McClish, and our first and only fellow, Denise Elser. The productivity of this group attests to the talent and drive of all those who were involved from the beginning and also of those who followed.

\section{Quality of life}

The assessment/evaluation of outcomes was a topic of continuous interest within our group. Assessing success or failure of a specific intervention needed a domain that included quality of life. Urinary incontinence is a social-hygienic issue affecting quality of life. Therefore such a domain had to be included within the spectrum of objective outcomes. The work of S. A. Schumaker [3], represents a stepping stone toward recognition of this element of assessment when evaluating treatment results in managing incontinence. The work was the product of several years of painstaking validity and internal/external reliability studies. A short form followed, and other tools applicable to specific conditions of the pelvic floor were developed by other groups.

\section{Subspecialty recognition}

I thought that since the government was recognizing the importance of urogynecology with grant dollars, it was only logical that the American Board of Obstetrics \& Gynecology would recognize it as a subspecialty. I was somewhat naïve to believe that this would occur promptly. Many years passed between the first pitch for subspecialty recognition that Dr. Henry Thiede and I made to the board and recognition by the Accreditation Council for Graduate Medical Education (ACGME) in 2013.

\section{The Jack Robertson Lifetime Achievement Award}

The American Urogynecologic Society recognized me with this most prestigious award. This honor I wish to share with all the colleagues who throughout all these years have interacted with me directly or indirectly; those with whom I shared hours 
of work and, yes, hours of fun as well. This includes all my friends and colleagues who are members of the American Urogynecologic Society and/or the Society of Gynecologic Surgeons. In particular, I'd like to share this honor with those who worked with me in the initial production of "Educational Objectives for Postgraduate Education in Gynecologic Urology" (the "little red book") as well as those involved in the production of the "Clinical Practice Guidelines for Urinary Incontinence in Adults" [4].

\section{Urogynecology going forward}

As our specialty moves forward it should always make maximal effort to ensure that any new diagnostic or therapeutic procedure benefits our patients and is backed by meticulous science. Frankly, the only times that I have seen members of our subspecialty make a misstep have been when they allowed people or groups with other interests or agendas to influence their thinking.

I am extremely optimistic about the future of urogynecology. Our subspecialty will continue to make great strides forward. I make this prediction based on the enormous talent shown by younger people who have joined us. Their ability to use technology to find and conduct research is astonishing.

I am also confident that urogynecology has strong leaders who will guide and drive its expansion. I don't know that I could ever repay the debt I owe to Dr. Dunn. I can only say I tried to follow his example with those whom I tried to mentor.

\section{References}

1. Jeffcoate TNA, Francis WJ (1966) Urgency incontinence in the female. Am J Obstet Gynecol 94(5):604-618

2. Fantl JA, Wyman JF, McClish DK et al (1991) Efficacy of bladder training in older women with urinary incontinence. JAMA 265:609613

3. Shumaker SA, Wyman JF, Uebersax JS, McClish DK, Fantl JA (1994) Health-related quality of life measures for women with urinary incontinence: the incontinence impact questionnaire in the urogenital distress inventory. Qual Life Res 3:291-306

4. (1994) Clinical Practice Guidelines for Urinary Incontinence in Adults. Health Care Policy and Research, US Dept. of Health. Washington 